Virginia Commonwealth University VCU Scholars Compass

2015

\title{
Identification of point defects in HVPE-grown GaN by steady-state and time-resolved photoluminescence
}

Michael A. Reshchikov

Virginia Commonwealth University,mreshchi@vcu.edu

Denis O. Demchenko

Virginia Commonwealth University

A Usikov

Nitride Crystals, Inc.

H Helava

Nitride Crystals, Inc.

Yu. Makarov

Nitride Crystals, Inc.

Follow this and additional works at: https://scholarscompass.vcu.edu/frsc_pubs

Part of the Physics Commons

(C) 2015 Society of Photo-Optical Instrumentation Engineers (SPIE)

\section{Downloaded from}

https://scholarscompass.vcu.edu/frsc_pubs/4

This Conference Proceeding is brought to you for free and open access by the Dept. of Forensic Science at VCU Scholars Compass. It has been accepted for inclusion in Forensic Science Publications by an authorized administrator of VCU Scholars Compass. For more information, please contactlibcompass@vcu.edu. 


\title{
Identification of point defects in HVPE-grown GaN by steady-state and time-resolved photoluminescence
}

\author{
M. A. Reshchikov, ${ }^{a,}{ }^{*}$ D. O. Demchenko, ${ }^{a}$ A. Usikov, ${ }^{b, c}$ H. Helava, ${ }^{b}$ and Yu. Makarov ${ }^{b}$ \\ ${ }^{a}$ Department of Physics, Virginia Commonwealth University, Richmond, VA 23284, USA; ${ }^{\mathrm{b}}$ Nitride \\ Crystals, Inc., Deer Park, NY 11729, USA; ${ }^{c}$ Saint-Petersburg National Research University of \\ Information Technologies, Mechanics and Optics, Saint Petersburg, Russia
}

\begin{abstract}
We have investigated point defects in GaN grown by HVPE by using steady-state and time-resolved photoluminescence (PL). Among the most common PL bands in this material are the red luminescence band with a maximum at $1.8 \mathrm{eV}$ and a zero-phonon line (ZPL) at $2.36 \mathrm{eV}$ (attributed to an unknown acceptor having an energy level $1.130 \mathrm{eV}$ above the valence band), the blue luminescence band with a maximum at $2.9 \mathrm{eV}$ (attributed to $\mathrm{Zn}_{\mathrm{Ga}}$ ), and the ultraviolet luminescence band with the main peak at $3.27 \mathrm{eV}$ (related to an unknown shallow acceptor). In GaN with the highest quality, the dominant defect-related PL band at high excitation intensity is the green luminescence band with a maximum at about $2.4 \mathrm{eV}$. We attribute this band to transitions of electrons from the conduction band to the 0/+ level of the isolated $\mathrm{C}_{\mathrm{N}}$ defect. The yellow luminescence (YL) band, related to transitions via the $-/ 0$ level of the same defect, has a maximum at $2.1 \mathrm{eV}$. Another yellow luminescence band, which has similar shape but peaks at about $2.2 \mathrm{eV}$, is observed in less pure $\mathrm{GaN}$ samples and is attributed to the $\mathrm{C}_{\mathrm{N}} \mathrm{O}_{\mathrm{N}}$ complex. In semi-insulating GaN, the GL2 band with a maximum at $2.35 \mathrm{eV}$ (attributed to $\mathrm{V}_{\mathrm{N}}$ ) and the $\mathrm{BL} 2$ band with a maximum at $3.0 \mathrm{eV}$ and the $\mathrm{ZPL}$ at $3.33 \mathrm{eV}$ (attributed to a defect complex involving hydrogen) are observed. We also conclude that the gallium vacancy-related defects act as centers of nonradiative recombination.
\end{abstract}

Keywords: photoluminescence, point defects, GaN, HVPE

\section{INTRODUCTION}

Gallium nitride is very promising material for high-power electronics. The hydride vapor phase epitaxy (HVPE) technique, which is currently used for the growth of thick GaN films or freestanding templates, has several advantages including fast growth rate, a very low density of dislocations, and a low concentration of point defects. Further improvement of the material quality is hindered by poor understanding of point defects in GaN. Photoluminescence (PL) is a powerful tool for studying point defects in semiconductors; however, most of the defect-related PL bands in GaN remain unidentified. ${ }^{1}$ In this work, we analyze PL from a large number of HVPE GaN samples including GaN layers on sapphire and freestanding GaN, undoped and Fe-doped. The experimental results are compared with the latest theoretical predictions. Based on this comparison, a number of point defects responsible for dominant PL bands in GaN are identified.

\section{EXPERIMENTAL}

Undoped 10-30 $\mu$ m-thick GaN films were grown by HVPE on c-plane 2-inch sapphire substrates at atmospheric pressure in argon ambient at temperatures of 850-1000 ${ }^{\circ} \mathrm{C}$. The room-temperature concentration of free electrons in these samples is between $2 \times 10^{16}$ and $4 \times 10^{17} \mathrm{~cm}^{-3}$, as was determined from the Hall-effect measurements. Two samples in this study were grown at Kyma Technologies. These were $450 \mu \mathrm{m}$-thick, semi-insulating $\mathrm{GaN}$ templates doped with Fe.

Steady-state and time-resolved PL was excited with $\mathrm{He}-\mathrm{Cd}$ and $\mathrm{N}$ lasers, respectively. Calibrated neutral-density filters were used to attenuate the excitation power density $\left(P_{\text {exc }}\right)$ over the range $10^{-3}-0.2 \mathrm{~W} / \mathrm{cm}^{2}$. A closed-cycle optical cryostat was used for temperatures between 15 and $320 \mathrm{~K}$. Other details can be found in Refs. 2 and 3. All samples were studied under identical conditions.

\footnotetext{
*mreshchi@vcu.edu; phone 18048281613
} 


\section{RESULTS AND DISCUSSION}

\subsection{Theoretical predictions}

We have calculated defect formation energies by using exchange tuned Heyd-Scuseria-Ernzerhof (HSE) hybrid functional $^{4}$ for all possible charge states of several common defects expected to form in GaN., ${ }^{5,6,8}$ The method accurately reproduces relevant bulk properties of $\mathrm{GaN}$, such as the bandgap, lattice constants, electron and hole effective masses (band curvature), etc. The details of the calculation method and corrections schemes to the defect energies can be found in Refs. 5 and 6 The computed thermodynamic transition levels for select defects are shown in Fig. 1. The thermodynamic transitions are transitions between two relaxed lattice geometries of two charge states and correspond to zero-phonon lines (ZPL) in the PL spectrum. The maxima of defect-related PL bands are observed at lower photon energies, because optical transitions occur in an essentially fixed lattice.

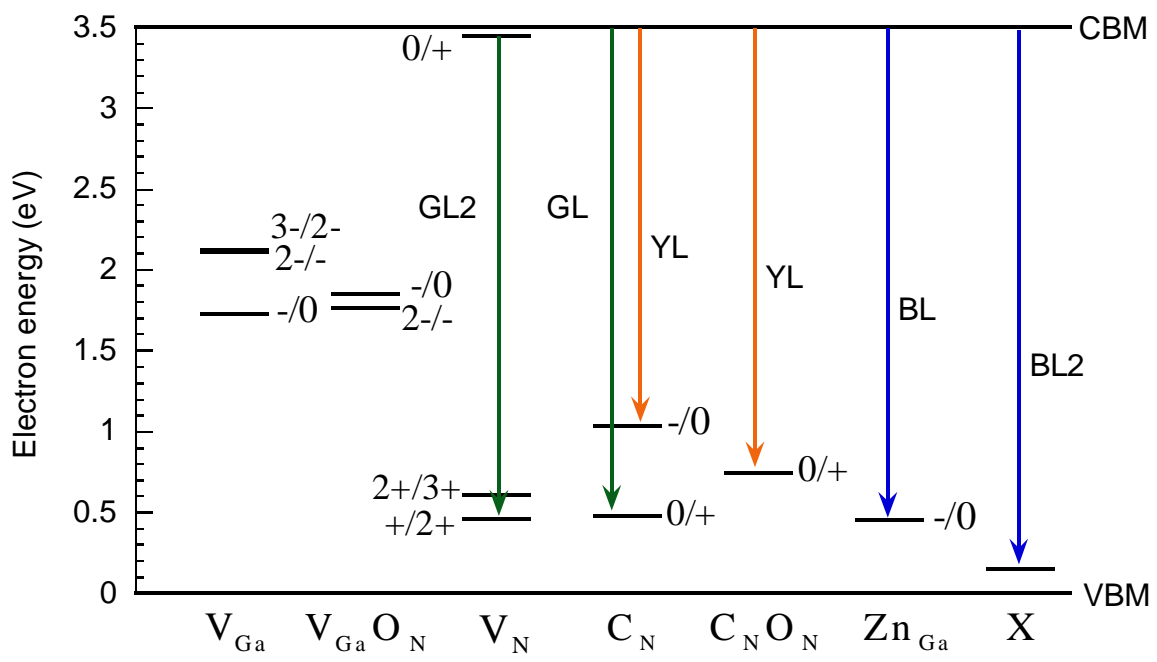

Fig. 1. Thermodynamic transition levels for defects in GaN. $\mathrm{X}$ is an unidentified defect, possibly complex involving hydrogen and one or two other elemental defects. Vertical arrows indicate optical transitions resulting in PL bands with labels next to the arrows. The length of the arrows corresponds to the ZPL energies.

The isolated gallium vacancy $\left(\mathrm{V}_{\mathrm{Ga}}\right)$ is predicted to have the 3-/2-, 2-/-, and -/0 thermodynamic transition levels at $2.12,2.11$, and $1.73 \mathrm{eV}$, respectively, from the valence band maximum $(\mathrm{VBM}){ }^{5}$ The negatively charged gallium vacancy is also expected to form a complex with shallow donor oxygen, which is always present in $\mathrm{GaN}$. The $\mathrm{V}_{\mathrm{Ga}} \mathrm{O}_{\mathrm{N}}$ complex has much lower formation energy than $\mathrm{V}_{\mathrm{Ga}}$, and its $2-/$ - and $-/ 0$ transition levels are calculated at 1.76 and 1.85 $\mathrm{eV}$, respectively, from the VBM. ${ }^{5}$ Due to strong electron-phonon coupling, the optical transitions of electrons from the conduction band to the 2-/- level of $\mathrm{V}_{\mathrm{Ga}} \mathrm{O}_{\mathrm{N}}$ are predicted to have a maximum at $1.53 \mathrm{eV}$, i.e. in the infrared region. ${ }^{5}$ The nitrogen vacancy $\left(\mathrm{V}_{\mathrm{N}}\right)$ has the $2+/ 3+,+/ 2+$ levels at 0.61 and $0.46 \mathrm{eV}$, respectively, above the $\mathrm{VBM}$ and a $0 /+$ level very close to the $\mathrm{CBM}^{7}{ }^{7}$ While the $\mathrm{V}_{\mathrm{Ga}}$-related defects are expected to form in conductive $n$-type $\mathrm{GaN}, \mathrm{V}_{\mathrm{N}}$ is expected to form in $p$-type or semi-insulating $\mathrm{GaN}$, providing certain compensating effect. From impurities, carbon, silicon, and oxygen are common contaminants in $\mathrm{GaN}$ growth. It is well known that $\mathrm{Si}_{\mathrm{Ga}}$ and $\mathrm{O}_{\mathrm{N}}$ are shallow donors. Our calculations show that carbon substitutes for nitrogen $\left(\mathrm{C}_{\mathrm{N}}\right)$, where it acts mostly as a deep acceptor, and also likely to form the $\mathrm{C}_{\mathrm{N}} \mathrm{O}_{\mathrm{N}}$ complex. The $-/ 0$ and $0 /+$ transition levels of $C_{N}$ are calculated at 1.04 and $0.48 \mathrm{eV}$ above the VBM. ${ }^{5,6}$ The $0 /+$ level of $\mathrm{C}_{\mathrm{N}} \mathrm{O}_{\mathrm{N}}$ is at $0.75 \mathrm{eV}$ above the VBM. Curiously, the optical transitions of electrons from the conduction band to the $-/ 0$ level of $\mathrm{C}_{\mathrm{N}}$ and to the 0/+ level of $\mathrm{C}_{\mathrm{N}} \mathrm{O}_{\mathrm{N}}$ have similar properties and close PL maxima (at 1.98 and $2.25 \mathrm{eV}$, respectively, above the VBM) and both can contribute to the omnipresent YL band in GaN. ${ }^{5}$ Zinc is another common contaminant in GaN grown by HVPE technique. The - $/ 0$ level of the $\mathrm{Zn}_{\mathrm{Ga}}$ acceptor is calculated at $0.45 \mathrm{eV}$ above the VBM. ${ }^{8}$ The optical transitions of electrons from the conduction band to the $\mathrm{Zn}_{\mathrm{Ga}}$ acceptor are expected to have a maximum at $2.94 \mathrm{eV}$. Since $\mathrm{Zn}_{\mathrm{Ga}}$ is one of the few defects producing a reliably identified PL band in GaN, the close agreement between calculated properties of $\mathrm{Zn}_{\mathrm{Ga}}$ and PL measurements demonstrates the accuracy of the theoretical approach. 


\subsection{The YL and GL bands}

In high-purity HVPE GaN samples, the green luminescence (GL) band with a maximum at $2.4 \mathrm{eV}$ is observed. It is usually observed at high excitation intensity because its intensity increases as a square of $P_{\text {exc }}$. As shown in Fig. 2a, the GL band becomes the dominant defect-related band at $P_{\mathrm{exc}}>0.2 \mathrm{~W} / \mathrm{cm}^{2}$. It is easier to detect the GL band in timeresolved PL experiments because it is very strong at short time delays after the excitation pulse (Fig. 2b). The decay of the GL band is exponential at temperatures between 30 and $100 \mathrm{~K}$, and the characteristic PL lifetime is $1-2 \mu$ s in this temperature range. At time delays longer than $10^{-5} \mathrm{~s}$, the GL band disappears, giving the way to the YL band with a maximum at $2.1 \mathrm{eV}$. The YL band decays much slower, with a typical PL lifetime of several milliseconds.
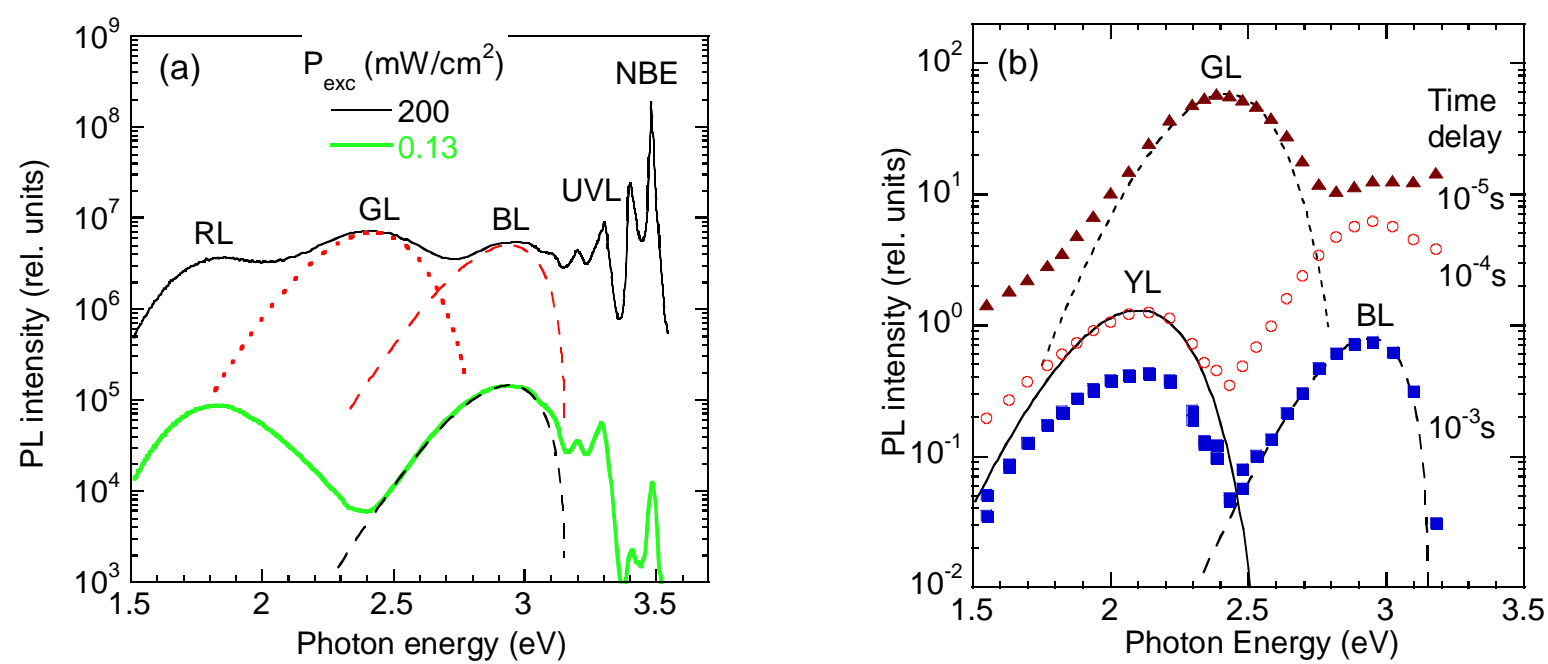

Fig. 2. PL spectra from HVPE GaN (sample RS280) at $100 \mathrm{~K}$. (a) Steady-state PL. (b) Time-resolved PL spectra. The dashed and dotted lines are calculated using Eq. (1) with the following parameters: $S_{e}=8.5, E_{0}+0.5 \hbar \Omega=2.92 \mathrm{eV}$, and $\hbar \omega_{\max }=2.42 \mathrm{eV}$ (the GL band), $S_{e}=7.4, E_{0}+0.5 \hbar \Omega=2.60 \mathrm{eV}$, and $\hbar \omega_{\max }=2.10 \mathrm{eV}$ (the YL band), and $S_{e}=2.2, E_{0}+$ $0.5 \hbar \Omega=3.15 \mathrm{eV}$, and $\hbar \omega_{\max }=2.94 \mathrm{eV}$ (the BL band).

The shapes of the GL and YL bands at low temperature can be modeled with the following formula derived from a one-dimensional configuration coordinate model: ${ }^{7}$

$$
I^{P L}(\hbar \omega) \propto \exp \left[-2 S_{e}\left(\sqrt{\frac{E_{0}+0.5 \hbar \Omega-\hbar \omega}{E_{0}+0.5 \hbar \Omega-\hbar \omega_{\max }}}-1\right)^{2}\right],
$$

where $S_{e}$ and $\hbar \Omega$ are the Huang-Rhys factor and the dominant phonon energy for the excited state, $\hbar \omega$ is the photon energy, $\hbar \omega_{\max }$ is the energy of the PL band maximum, and $E_{0}$ is the zero-phonon line (ZPL) energy. The vibrational parameters of the defects responsible for the GL and YL bands are given in the caption to Fig. 2.

The YL and GL bands in high-purity HVPE GaN samples are attributed to transitions of electrons from the conduction band to the $-/ 0$ and $0 /+$ levels of the isolated $\mathrm{C}_{\mathrm{N}}$ defect. ${ }^{5}$ The positions of the PL band maxima $(2.1 \mathrm{eV}$ for the YL band and $2.4 \mathrm{eV}$ for the GL band) and the ZPL energy (2.57 eV for the YL band and $2.9 \mathrm{eV}$ for the GL band) agree with the calculated values $\left(\hbar \omega_{\max }=1.98 \mathrm{eV}\right.$ and $E_{0}=2.45 \mathrm{eV}$ for the $\mathrm{YL}$ band and $\hbar \omega_{\max }=2.59 \mathrm{eV}$ and $E_{0}=3.0 \mathrm{eV}$ for the GL band). ${ }^{5}$ In less pure HVPE GaN samples and in samples grown by metalorganic chemical vapor deposition (MOCVD) we observed only the YL band with a maximum at $2.2 \mathrm{eV}$. We propose that in these samples carbon and oxygen impurities form the $\mathrm{C}_{\mathrm{N}} \mathrm{O}_{\mathrm{N}}$ complexes, the concentration of which exceeds the concentration of isolated $\mathrm{C}_{\mathrm{N}}$. The maximum of the $\mathrm{YL}$ band caused by the $\mathrm{C}_{\mathrm{N}} \mathrm{O}_{\mathrm{N}}$ complexes is expected at slightly higher photon energies $(2.25 \mathrm{eV})$, in agreement with the experimental results. ${ }^{5,6}$ Since the positions and shapes of the YL bands caused by the $\mathrm{C}_{\mathrm{N}}$ and $\mathrm{C}_{\mathrm{N}} \mathrm{O}_{\mathrm{N}}$ defects are very similar, these defects can be better distinguished by the presence (in case of $\mathrm{C}_{N}$ ) or absence (in case of $\mathrm{C}_{\mathrm{N}} \mathrm{O}_{\mathrm{N}}$ ) of the follow up GL band because only the isolated $\mathrm{C}_{\mathrm{N}}$ defect is expected to cause a higher energy PL band with increasing excitation intensity (Fig. 1). 


\subsection{The RL, BL, and UVL bands in HVPE GaN}

In many HVPE GaN samples the red luminescence (RL) band with a maximum at $1.8 \mathrm{eV}$ is the dominant defect-related PL band (Fig. 3). In some samples, fine structure on the high-energy side of this band can be observed with an abrupt drop at $\sim 2.36 \mathrm{eV}$. The sharp peak at $2.36 \mathrm{eV}$ is identified as the ZPL line of the RL band. ${ }^{9}$ The RL band is caused by transitions of electrons from a shallow donor (at low temperature) or from the conduction band (at elevated temperatures) to an unknown defect level located at $1.13 \mathrm{eV}$ above the VBM.

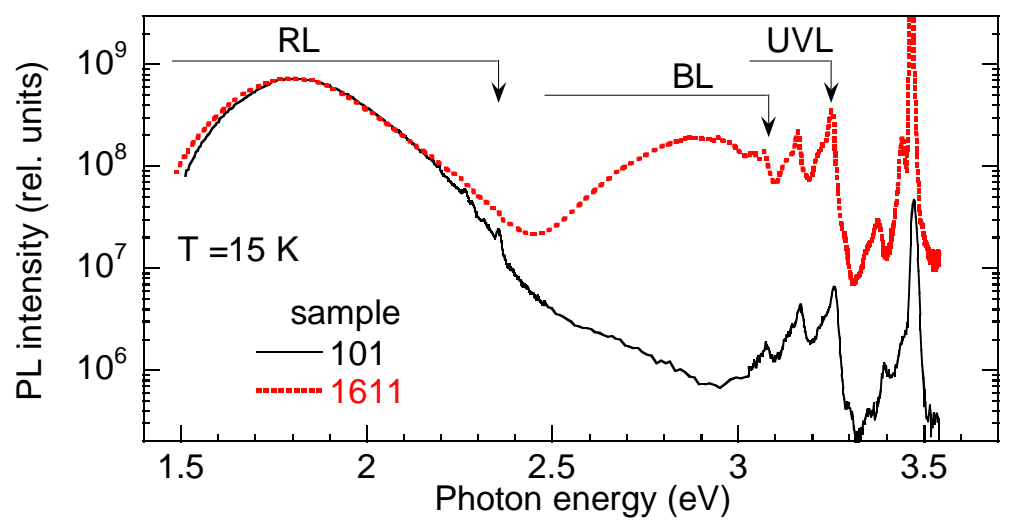

Fig. 3. Low-temperature PL spectra from HVPE GaN. The arrows indicate positions of the ZPL for each defect-related PL band.

The blue luminescence (BL) band is observed in undoped and Zn-doped GaN grown by MOCVD and HVPE. It has a maximum at $2.9 \mathrm{eV}$ and a characteristic fine structure on its high-energy side, with the ZPL line at 3.1 eV. The BL band in these samples is attributed to transitions of electrons from a shallow donor (at low temperature) or from the conduction band (at elevated temperatures) to the $\mathrm{Zn}_{\mathrm{Ga}}$ acceptor. ${ }^{1}$ This acceptor is very efficient in capturing photogenerated holes. As a result, the BL band can be detected even in GaN samples with the concentration of $\mathrm{Zn}$ lower than $10^{14} \mathrm{~cm}^{-3}$, which is well below the detection limit in the secondary ion mass-spectrometry measurements. ${ }^{10}$ The source of $\mathrm{Zn}$ in HVPE-grown GaN is either contamination of Ga metal with $\mathrm{Zn}$ or the "memory effect" when $\mathrm{Zn}$-doping was used in an HVPE reactor.

The ultraviolet luminescence (UVL) band has a main peak at $3.27 \mathrm{eV}$ followed by a few LO phonon replicas. It is observed at temperatures below $100 \mathrm{~K}$ in PL spectra from conductive GaN grown by HVPE (Figs. 2 and 3). This PL band is often referred to as the shallow donor-acceptor pair (DAP) band because at low temperatures the band is caused by transitions of electrons from shallow donors to shallow acceptors. At temperatures above $40 \mathrm{~K}$, the DAP-type transitions are replaced with transitions of electrons from the conduction band to the same shallow acceptor (eA transitions). ${ }^{1,9}$ In samples contaminated with $\mathrm{Mg}$, the UVL band is caused by the $\mathrm{Mg}_{\mathrm{Ga}}$ acceptor. ${ }^{1}$ It is possible that other shallow acceptors may cause very similar UVL band; however the identity of such shallow acceptors remains unclear. Recent developments indicate that carbon acceptor can be ruled out as possible candidate for this defect. Indeed, contrary to early reports based on theoretical calculations ${ }^{11}$ and experimental works, ${ }^{12}$ that $\mathrm{C}_{\mathrm{N}}$ is a shallow acceptor and can even be responsible for $p$-type conductivity, ${ }^{13,14}$ recent calculations indicate that $\mathrm{C}_{\mathrm{N}}$ is a deep acceptor. ${ }^{6,15}$ Moreover, the intensity of the UVL band is sometimes extremely low in C-doped GaN, and the concentration of the shallow acceptors in these samples may be several orders of magnitude lower than the concentration of carbon impurities. ${ }^{16}$

\subsection{The GL2 and BL2 bands in semi-insulating GaN}

In semi-insulating GaN, especially in GaN grown in Ga-rich conditions, the GL2 band with a maximum at 2.35-2.36 eV can be observed (Fig. 4). ${ }^{7}$ It can also be detected after mechanical polishing of the surface in high-purity freestanding GaN grown by HVPE. ${ }^{17}$ The shape of the GL2 band at low temperature can be modeled with Eq. (1). ${ }^{7}$ The vibrational parameters of the defect responsible for the GL2 band $\left(\hbar \Omega=23 \mathrm{meV}, S_{e}=26.5, E_{0}=2.85 \mathrm{eV}\right.$, and $\hbar \omega_{\max }=2.35 \mathrm{eV}$ agree well with the parameters for $\mathrm{V}_{\mathrm{N}}$ in $\mathrm{GaN}$ calculated by Alkauskas et al. ${ }^{18}$ In contrast to majority of defect-related PL bands in GaN, the PL decay for the GL2 band after a pulsed excitation is exponential at low temperatures (15-100 K), 
with a characteristic PL lifetime of about $0.3 \mathrm{~ms}$. This unusual behavior was explained by an internal transition, where an electron weakly localized at the shallow donor-like $0 /+$ state collapses to the localized orbital, and the defect converts from $\mathrm{V}_{\mathrm{N}}^{2+}$ to $\mathrm{V}_{\mathrm{N}}^{+}$(Fig. 1). ${ }^{7}$ The $+/ 2+$ transition level of $\mathrm{V}_{\mathrm{N}}$ is calculated to be at $0.46 \mathrm{eV}$ above the VBM. ${ }^{5}$ This value agrees well with the activation energy in the thermal quenching of the GL2 band $(0.4 \mathrm{eV})$ and with position of the ZPL energy required for the best fit of the experimental shape of the GL2 band. ${ }^{5}$

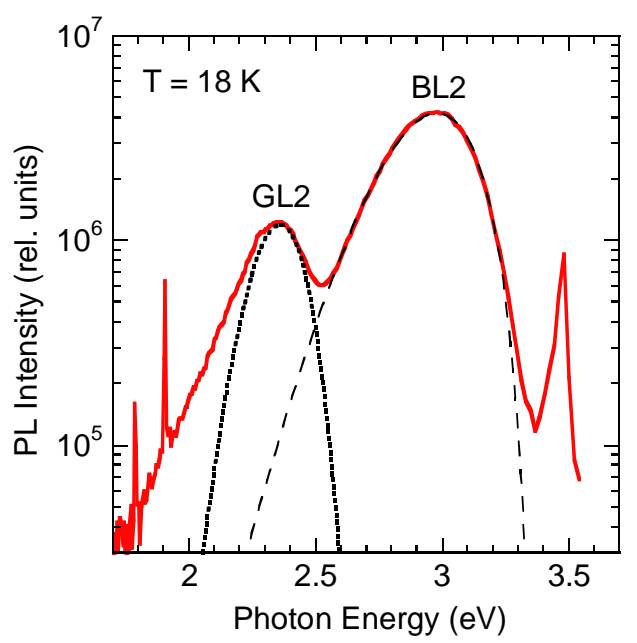

Fig. 4. Low-temperature PL spectrum from semi-insulating Fe-doped GaN grown by HVPE at Kyma Technologies (freestanding GaN, sample AE2148.5, Ga face after chemical-mechanical polishing). $P_{\text {exc }}=0.01 \mathrm{~W} / \mathrm{cm}^{2}$. The dashed and dotted curves are calculated using Eq. (1) with the following parameters: $S_{e}=26.5, E_{0}+0.5 \hbar \Omega=2.87 \mathrm{eV}$, and $\hbar \omega_{\max }=$

$2.36 \mathrm{eV}$ (the GL2 band) and $S_{e}=4.5, E_{0}+0.5 \hbar \Omega=3.35 \mathrm{eV}$, and $\hbar \omega_{\max }=2.36 \mathrm{eV}$ (the BL2 band).

The BL2 band has a maximum at $3.0 \mathrm{eV}$, the $\mathrm{ZPL}$ at $3.33 \mathrm{eV}$, and the characteristic phonon structure on its highenergy side. ${ }^{1}$ It appears only in semi-insulating GaN samples grown by MOCVD or HVPE techniques. The shape of the BL2 band in two HVPE freestanding GaN samples is shown in Fig. 5. The BL2 band is unstable: it is bleaching under

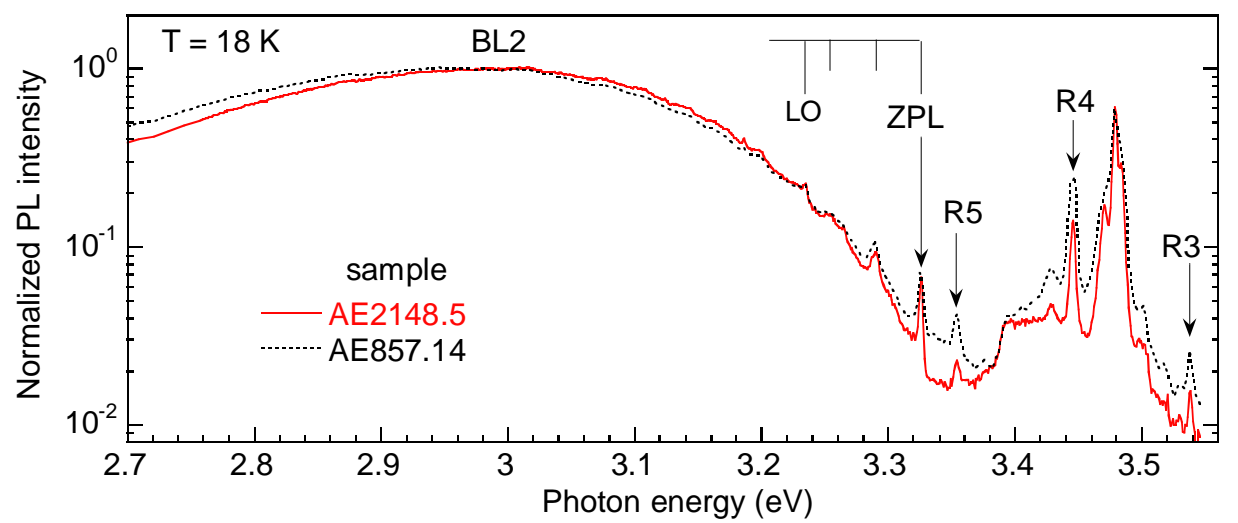

Fig. 5. Low-temperature PL spectrum from semi-insulating, Fe-doped, freestanding GaN grown by HVPE at Kyma Technologies. $P_{\text {exc }}=0.2 \mathrm{~W} / \mathrm{cm}^{2}$. The strongest exciton peak is at $3.479 \mathrm{eV}$. The ZPL for the BL2 band at $3.326 \mathrm{eV}$ and the fine structure formed by emission of local phonons with energy $36 \mathrm{meV}$ and LO phonon with energy $92 \mathrm{meV}$ are identical in the two samples. The BL2 band has a maximum at $3.0 \mathrm{eV} \mathrm{eV} \mathrm{(AE2148.5)} \mathrm{and} 3.297 \mathrm{eV}$ (AE857.14). The shape of the latter is apparently distorted by another PL band at lower photon energies. The lines at 3.538, 3.446, and $3.356 \mathrm{eV}$, labeled R3, R4, and R5, respectively, are the resonant Raman lines. 
continuous UV illumination. ${ }^{19,20}$ Simultaneously, the intensity of the YL band with a maximum at $2.2 \mathrm{eV}$ increases. It was suggested that the BL2 band is caused by a defect complex containing hydrogen, and that dissociation of this complex under UV illumination is responsible for the bleaching of the BL2 band. ${ }^{19}$ Since the YL band is caused by the $\mathrm{C}_{\mathrm{N}}$ and $\mathrm{C}_{\mathrm{N}} \mathrm{O}_{\mathrm{N}}$ defects, it is logical to assign the BL2 band to the $\mathrm{C}_{\mathrm{N}} \mathrm{H}$ or $\mathrm{C}_{\mathrm{N}} \mathrm{O}_{\mathrm{N}} \mathrm{H}$ complexes. Preliminary estimates indicate that the transition level responsible for the BL2 band is located at $0.15 \mathrm{eV}$ above the VBM. ${ }^{20,21}$ The decay of the BL2 band after a pulsed excitation is exponential at low temperature, with a characteristic lifetime of about $0.4 \mu \mathrm{s}^{21}$

\subsection{Gallium vacancy-related defects}

It is widely believed that $\mathrm{V}_{\mathrm{Ga}}$, or more likely the $\mathrm{V}_{\mathrm{Ga}} \mathrm{O}_{\mathrm{N}}$ complex, is responsible for the YL band in GaN. Such attribution was dericed from early density functional theory (DFT) calculations, which predicted the 3-/2- level of $\mathrm{V}_{\mathrm{Ga}}$ and the 2-/- level of $\mathrm{V}_{\mathrm{Ga}} \mathrm{O}_{\mathrm{N}}$ at $1.1 \mathrm{eV}$ above the VBM. ${ }^{22}$ From experimental side, a correlation between the concentration of the $\mathrm{V}_{\mathrm{Ga}}$-related defects and intensity of the $\mathrm{YL}$ band was reported, ${ }^{23}$ yet no such correlation was found in several other works. ${ }^{24,25,26}$ The positron annihilation spectroscopy (PAS) studies indicated that the concentration of the $\mathrm{V}_{\mathrm{Ga}}-$ related defects can reach $10^{19} \mathrm{~cm}^{-3}$ in $n$-type $\mathrm{GaN},{ }^{23,27}$ and that the $\mathrm{V}_{\mathrm{Ga}} \mathrm{O}_{\mathrm{N}}$ complex is the dominant $\mathrm{V}_{\mathrm{Ga}}-\mathrm{related}$ defect, whereas the isolated $\mathrm{V}_{\mathrm{Ga}}$ becomes mobile and diffuses out at temperatures exceeding $600 \mathrm{~K} \cdot{ }^{28,29,30}$ According to our recent calculations ${ }^{5,6}$ optical transitions of electrons from the conduction band to the 2-/- level of the $\mathrm{V}_{\mathrm{Ga}} \mathrm{O}_{\mathrm{N}}$ is expected to produce a PL band with a maximum at $1.53 \mathrm{eV}$ and the zero-phonon line (ZPL) at $1.74 \mathrm{eV}$ in $n$-type GaN. The PL band related to the isolated $\mathrm{V}_{\mathrm{Ga}}$ is also expected in the infrared region. Since such bands are not observed in $n$-type GaN, our calculations suggest that recombination involving the $\mathrm{V}_{\mathrm{Ga}}-$ related defects is nonradiative. Nonradiative defects can be detected by other techniques. In particular, optical deep-level transient spectroscopy (ODLTS) can determine energy levels of hole traps. The $\mathrm{H} 5$ trap appears to be a good candidate for the $\mathrm{V}_{\mathrm{Ga}} \mathrm{O}_{\mathrm{N}}$ complex. It is the dominant hole trap in bulk, undoped GaN grown by HVPE, with the concentration in the mid $10^{15} \mathrm{~cm}^{-3} .31,32$ The H5 trap was also observed in MOCVD-grown GaN, but only after irradiation with neutrons, which is expected to introduce vacancy-related defects. ${ }^{33}$ The photoionization spectrum for the $\mathrm{H} 5$ trap showed a threshold at $2.1-2.2 \mathrm{eV} .{ }^{32}$ If the related recombination were radiative, the PL band would have a maximum at photon energies lower than $2.0 \mathrm{eV}$, which disagrees with the position of the YL band.

Son et al. ${ }^{34}$ detected the $\mathrm{V}_{\mathrm{Ga}} \mathrm{O}_{\mathrm{N}}$ complex by electron paramagnetic resonance technique in freestanding GaN grown by HVPE and irradiated with 2-MeV electrons. A strong D2 signal appeared after illumination with photon energies above $1.24 \mathrm{eV}$ and was identified as the excitation of electrons from the 2-/- level of $\mathrm{V}_{\mathrm{Ga}} \mathrm{O}_{\mathrm{N}}$ to the conduction band or to electron traps lying close to the CBM. The position of this threshold roughly agrees with our calculations for 2-/- level of $\mathrm{V}_{\mathrm{Ga}} \mathrm{O}_{\mathrm{N}}\left(1.74 \mathrm{eV}\right.$ below the CBM) and disagrees with the earlier DFT calculations $(2.4 \mathrm{eV}$ below the $\mathrm{CBM}){ }^{22}$ Thus, we conclude that the $\mathrm{V}_{\mathrm{Ga}}$-related defects contribute to nonradiative recombination and are anlikely to be related to the $\mathrm{YL}$ band as was widely accepted in last two decades. ${ }^{1}$

\section{CONCLUSIONS}

We have studied defect-related PL in GaN grown by HVPE technique. The RL band with a maximum at $1.8 \mathrm{eV}$ in undoped GaN is caused by an unknown acceptor having an energy level at $1.13 \mathrm{eV}$ above the VBM. The GL band with a maximum at $2.4 \mathrm{eV}$ in high-purity $\mathrm{GaN}$ is attributed to transitions via the $0 /+$ level of isolated $\mathrm{C}_{\mathrm{N}}$ defect, whereas the $\mathrm{YL}$ band with a maximum at $2.1 \mathrm{eV}$ is caused by transitions via the $-/ 0$ level of the same defect. In less pure GaN samples, the $\mathrm{YL}$ band with a maximum at $2.2 \mathrm{eV}$ is attributed to the $\mathrm{C}_{\mathrm{N}} \mathrm{O}_{\mathrm{N}}$ complex. The $\mathrm{BL}$ band with a maximum at $2.9 \mathrm{eV}$ and the UVL band with the main peak at $3.27 \mathrm{eV}$ are assigned to the $\mathrm{Zn}_{\mathrm{Ga}}$ acceptor and unknown shallow acceptor, respectively. In semi-insulating GaN, the GL2 band with a maximum at $2.35 \mathrm{eV}$ and the BL2 band with a maximum at $3.0 \mathrm{eV}$ are observed. The former is caused by an internal transition in the $\mathrm{V}_{\mathrm{N}}$ defect. The structure of the defect responsible for the BL2 band is still uncertain; however, we can speculate that it is a complex defect involving hydrogen.

\section{ACKNOWLEDGMENTS}

The work at VCU was supported by the National Science Foundation (DMR-1410125) and the Thomas F. and Kate Miller Jeffress Memorial Trust. The authors are grateful to J. Leach from Kyma Technologies for providing freestanding GaN samples. Computational part of this work was performed at VCU Center for High Performance Computing. 


\section{REFERENCES}

[1] M. A. Reshchikov and H. Morkoç, J. Appl. Phys. 97, 061301 (2005).

[2] M. A. Reshchikov, A. Kvasov, T. McMullen, M. F. Bishop, A. Usikov, V. Soukhoveev, and V. A. Dmitriev, Phys. Rev. B 84, 075212 (2011).

[3] M. A. Reshchikov, J. Appl. Phys. 115, 103503 (2014).

[4] J. Heyd, G. E. Scuseria and M Ernzerhof, J. Chem. Phys. 118, 8207 (2003).

[5] M. A. Reshchikov, D. O. Demchenko, A. Usikov, H. Helava, and Yu. Makarov, Phys. Rev. B, 90, 235203 (2014).

[6] D. O. Demchenko, I. C. Diallo, and M. A. Reshchikov, Phys. Rev. Lett. 110, 087404 (2013).

[7] M. A. Reshchikov, D. O. Demchenko, J. D. McNamara, S. Fernández-Garrido, and R. Calarco, Phys. Rev. B 90, 035207 (2014).

[8] D. O. Demchenko and M. A. Reshchikov, Phys. Rev. B 88, 115204 (2013).

[9] M. A. Reshchikov, A. Usikov, H. Helava, and Yu. Makarov, Appl. Phys. Lett. 104, 032103 (2014).

[10] M. S. Mohajerani, M. A. Reshchikov, A. Behrends, A. Bakin, and A. Waag, Phys. Stat. Sol. (c) 10, 523 (2013).

[11] A. F. Wright, J. Appl. Phys. 92, 2575 (2002).

[12] R. Armitage, Q. Yang, and E. R. Weber, J. Appl. Phys. 97, 073524 (2005).

[13] C. R. Abernathy, J. D. MacKenzie, S. J. Pearton, and W. S. Hobson, Appl. Phys. Lett. 66, 1969 (1995).

[14] T. Hikosaka, N. Koide, Y. Honda, M. Yamaguchi, and N. Sawaki, Phys. Stat. Sol. (c) 3, 1425 (2006).

[15] J. L. Lyons, A. Janotti, and C. G. Van de Walle, Appl. Phys. Lett. 97, 152108 (2010).

[16] M. A. Reshchikov, R. H. Patillo, and K. C. Travis, Mater. Res. Soc. Symp. Proc. 892, FF23.12 (2006).

[17] J. D. McNamara, M. A. Foussekis, A. A. Baski, X. Li, V. Avrutin, H. Morkoç, J. H. Leach, T. Paskova, K. Udwary, E. Preble, and M. A. Reshchikov, Phys. Stat. Sol. (c) 10, 536 (2013).

[18] A. Alkauskas, J. L. Lyons, D. Steiauf, and C. G. Van de Walle, Phys. Rev. Lett. 109, 267401 (2012).

[19] M. A. Reshchikov, Y. T. Moon, and H. Morkoç, Phys. Stat. Sol. (c) 2, 2716 (2005).

[20] M. A. Reshchikov, Y. T. Moon, X. Gu, B. Nemeth, J. Nause, and H. Morkoç, Physica B, 376-377, 715 (2006).

[21] M. A. Reshchikov and H. Morkoç, Physica B, 376-377, 428 (2006).

[22] J. Neugebauer and C. G. Van de Walle, Appl. Phys. Lett. 69, 503 (1996).

[23] K. Saarinen, T. Laine, S. Kuisma, J. Nissilä, P. Hautojärvi, L. Dobrzynski, J. M. Baranowski, K. Pakula, R. Stepniewski, M. Wojdak, A. Wysmolek, T. Suski, M. Leszszynski, I. Grzegory, and S. Porowski, Phys. Rev. Lett. 79, 3030 (1997).

[24] F. Reurings and F. Tuomisto, Proc. of SPIE 6473, 64730M (2007).

[25] F. J. Xu, B. Shen, L. Lu, Z. L. Miao, J. Song, Z. J. Yang, G. Y. Zhang, X. P. Hao, B. Y. Wang, X. Q. Shen, and H. Okumura, J. Appl. Phys. 107, 023528 (2010).

[26] S. Suihkonen, H. Nykänen, T. Tanikawa, M. Yamaguchi, Y. Honda, and H. Amano, Phys. Stat. Sol. (a) 210, 383 (2013).

[27] J. Oila, V. Ranki, J. Kivioja, K. Saarinen, P. Hautojärvi, J. Likonen, J. M. Baranowski, K. Pakula, T. Suski, M. Leszczynski, and I. Grzegory, Phys. Rev. B 63, 045205 (2001).

[28] K. Saarinen, T. Suski, I. Grzegory, and D. C. Look, Phys. Rev. B 64, 233201 (2001).

[29] J. Oila, J. Kivioja, V. Ranki, K. Saarinen, D. C. Look, R. J. Molnar, S. S. Park, S. K. Lee, and J. Y. Han, Appl. Phys. Lett. 82, 3433 (2003).

[30] F. Tuomisto, Proc. of SPIE 6473, 647312 (2007).

[31] A. Y. Polyakov, I.-H. Lee, N. B. Smirnov, E. A. Kozhukhova, and S. J. Pearton, J. Appl. Phys. 109, 123701 (2011).

[32] I.-H. Lee, A. Y. Polyakov, N. B. Smirnov, A. V. Govorkov, A. S. Usikov, H. Helava, Yu. N. Makarov, and S. J. Pearton, J. Appl. Phys. 115, 223702 (2014).

[33] I.-H. Lee, A. Y. Polyakov, N. B. Smirnov, A. V. Govorkov, E. A. Kozhukhova, N. G. Kolin, V. M. Boiko, A. V. Korulin, and S. J. Pearton, J. Vac. Sci. Technol. 29, 041201 (2011).

[34] N. T. Son, C. G. Hemminingsson, T. Paskova, K. R. Evans, A. Usui, N. Morishita, T. Ohshima, J. Isoya, B. Monemar, and E. Janzén, Phys. Rev. B 80, 153202 (2009). 